\title{
EGU21-2326
}

https://doi.org/10.5194/egusphere-egu21-2326

EGU General Assembly 2021

(c) Author(s) 2021. This work is distributed under

the Creative Commons Attribution 4.0 License.

\section{Modelling the salinity response to fresh water flow and variable tidal amplitude in an idealized river delta}

\author{
Constantinos Matsoukis ${ }^{1}$, Laurent O. Amoudry ${ }^{2}$, Lucy Bricheno ${ }^{2}$, and Nicoletta Leonardi ${ }^{1}$ \\ ${ }^{1}$ University of Liverpool, School of Environmental Sciences, Department of Geography and Planning, Roxby Building, \\ Chatham St., Liverpool L69 7ZT, UK (c.matsoukis@liverpool.ac.uk) \\ ${ }^{2}$ National Oceanography Centre, Joseph Proudman Building, 6 Brownlow Street, Liverpool, Merseyside, L3 5DA, UK
}

High salinity values in deltaic regions can be detrimental for agriculture, aquaculture and human consumption. Salinity levels in river deltas could significantly increase due to sea level rise and infrastructure works such as river diversions or dam constructions. River flow and tides have a large influence on salinity concentrations and it is thus important to understand their combined role. In this paper, a 3D model is built for an idealized delta. A series of simulations is carried out to investigate salinity fields developed under the combined action of tidal amplitude and fresh water flow. Simulations are classified based on the ratio between fresh water and tidal range. Both tide influenced and river dominated cases were considered. Results emphasize the importance of tidally driven mixing which can establish fresher conditions in the delta for certain amplitudes. Tidal amplitude increase enhances the flow in the delta and enlarges the fresh water layer thickness and length. On the other hand, the maximum tidal ranges can limit significantly the fresh water volume. The spatiotemporal salinity distribution is described in terms of delta topology and network geometry. Salinity and river discharge were found to be negatively and exponentially correlated by an equation that resembles solutions of the 1D advection-diffusion equation. Large bathymetric differences between delta areas were identified to play a key role on the salinity patterns as they can modify the nature of the extracted relationships and correlations. 